\title{
THE INFLUENCE OF INFORMATION DELIVERY ON RISK RANKING BY LAY PEOPLE
}

Accepted for Publication, Journal of Risk Research, March 2006

\section{VIRNA VANEZA GUTIÉRREZ (*)}

Industrial Engineering Department

Universidad Diego Portales, Santiago, Chile

\section{LUIS ABDÓN CIFUENTES}

Industrial and Systems Engineering Department

Pontificia Universidad Católica de Chile

NICOLAS BRONFMAN CACERES

Engineering Sciences Department

Universidad Nacional Andrés Bello, Santiago, Chile

\section{(*) CORRESPONDING AUTHOR}

Industrial Engineering Department

Universidad Diego Portales

Av. Ejército libertador 441, 6to piso.

Zip Code: 837-0191

Phone number: +562-6762479

Fax: $+562-6768130$

E-mail: virna.gutierrez@udp.cl 


\begin{abstract}
An experiment was conducted in a real environment to test how information delivery affects risk ranking. Another aim was to propose the best format for delivering information. Different people received different types of information about risks in a risk ranking exercise: Group 1 received a descriptive paragraph about the hazards (Format 1); Group 2 added a table with specific information on risk attributes (Format 2); Group 3 added information on the steps taken locally to mitigate the risks (Format 3), and Group 4 received a data table without identifying the hazard (Format 4).

Agreement among subjects' rankings within a group and from group to group was used to measure the potential impact of information delivery. Average pair-wise Spearman correlation was used to compare the level of agreement within each group. Results showed greater consensus in group using Format 4 than in Format 1, 2, and 3, with the only significant difference between Format 4 and each one of the others.
\end{abstract}

The results show that the amount of information, and the way it is delivered, may affect how lay people rank risks, but the differences are not statistically significant. 


\section{Introduction}

Several intrinsic problems have been debated at length in the literature concerning the communication of risk information, including how it is presented (Slovic, 2000). Informing the public about environmental, health and safety issues is far from straightforward. Communicators must find a way of presenting inherently complex risk information in a comprehensible manner (Slovic, 2000).

Communication material and methods have to take into account how lay people perceive risk (Fischhoff et al., 1978; Morgan et al., 1992; Fischhoff, 1995; Fischhoff et al., 1997); incorporate how social background influences it (Vaughan \& Nordenstam, 1991; Savage, 1993; Vaughan, 1995; Gustafson, 1998; Hitchcock, 2000; Dosman et al., 2001; Johnson, 2002; Bronfman et al., 2003; Bronfman \& Cifuentes, 2003) as well as how personal experiences may influence beliefs as regards to specific hazards and situations (Bastide et al., 1989; Slovic et al., 1993; Flynn et al., 1994; Krewski et al., 1995; Glendon et al., 1996). Decision makers also need to bear in mind that lay people's perceptions differ markedly from those of experts (Kraus et al., 1992; Flynn et al., 1993).

When decision makers inform the public, they need to consider how people are likely to incorporate the new data within their existing knowledge. Communicators therefore ought to be aware of such limitations (Slovic et al., 1980; Morgan et al., 1992; Lundgren \& McMakin, 1998).

Lay people may need assistance in order to construct opinion-based judgments. It is crucial to inform the public not only of the risks themselves, but also to consider how the quantity and the way in which risk data is presented affects public attitudes and behavior (Slovic et al., 1985; Fischhoff, 1991). Several studies have found that significant shifts in risk perception can occur upon relatively minor changes in the amount of data presented (Kaplan \& B. Hammel, 1985; Loomis \& duVair, 1993), and in the way in which it is conveyed (Golding \& S. Krimsky, 1992)

Nearly all risk perception and ranking studies have been conducted in developed countries. However, socioeconomic and cultural differences between developed and developing countries may render the application of specific methods invalid: hence the need to conduct local studies.

This study attempts to find ways of incorporating the viewpoints of citizens as an input for the decision-making process in Chile regarding hazards to the public. Participation of the public is required as set forth in the Environmental Impact Assessment Code, which forms a part of Chile's General Environmental Law. At present, though, there are no legal procedures for sounding public concern and attitudes toward health and safety risks so public participation is taken into account $a d-h o c$.

Management of certain risks is a luxury, some say, even middle-income countries such as Chile can ill afford. Nevertheless, public concern about environmental issues is mounting in Chile so formal tools for gauging the public's opinion towards environmental and social risk are needed to put the scant available funds to good use. Therefore, risk ranking by citizens rather than solely by experts may prove a useful tool in developing countries.

Over the past few years, researchers at Carnegie Mellon University have developed a method to elicit public concerns about health, safety, and environmental hazards (DeKay et al., 2001; Willis, 2002). The method, designed to encourage deliberation about important characteristics 
of the hazards, encompasses five interdependent steps (DeKay et al., 2001; Florig et al., 2001): risk experts define and categorize the risks to be ranked, with input from the community (Step A); identify the relevant attributes of those risks (Step B); and describe the risks in a set of standardized risk summary sheets that ought to be the best format for communicating the risks (Step C). Jury-like groups of subjects are then selected and use these materials to rank the risks (Step D), and finally the investigators who executed the riskranking exercises report the process and the resulting rankings (Step E).

This method has been applied on a test bed involving the health and safety risks posed at a fictitious Middle School (DeKay et al., 2001) and on a test bed including ecological risks and their attributes at a fictitious county in the Midwestern U.S (Willis, 2002). The procedures elicited rankings that were consistent among participants and groups. Subjects were also satisfied with both the risk-ranking process and the results (DeKay et al., 2001). It should be borne in mind nevertheless that the method was applied to elicit concerns about hazards in hypothetical situations.

The general method of DeKay et al. may be applied to a developing country, but only after careful validation of each stage. Steps (A) and (B) were carried out based on the work of Bronfman and Cifuentes, who successfully replicated in Santiago, Chile the method used by Slovic, Fischhoff and Liechtenstein. The attributes and high-level factors found by and large coincided with classical studies. This study provided the basis for selecting the hazards and representative attributes. Summary sheets for step (C) were fashioned using local information, and were tested with residents of the borough in which the study was conducted. Surprisingly, we found that people's ranking of hazards varied little after summary sheets were provided. We could not determine whether narrative or quantitative information was responsible for this small change, and whether people fully understood the additional information. This dilemma motivated the current study in which we tested how information delivery affected the ranking of risks.

The main objectives of this study are to determine to what extent quantitative and qualitative information about risks, as well as how it is delivered, influences risk rankings made by lay people, and to identify the best information delivery format for conducting future risk ranking exercises.

The following hypotheses were tested:

$\mathrm{H}_{1}$ : The quantity and type of information provided does have a bearing on risk ranking.

$\mathrm{H}_{2}$ : Providing lay people with further information - characteristic of the hazard (attribute)results in better agreement.

$\mathrm{H}_{3}$ : Narrative information (which may cover previously held beliefs) is more important than attribute information.

$\mathrm{H}_{4}$ : When only presented with attribute data, people not told the name of the risk base their rankings on just one attribute: the expected number of deaths.

\section{Data and methods}

\subsection{STUDY DESIGN}

The risk-ranking experiments were conducted in a low to middle income borough in Santiago, Chile. For the case study, the Borough of Pudahuel was chosen as it is so well defined 
geographically it is almost a town within the city. Participants were required to rank hazards they are exposed to within their borough, according to their level of concern. The borough is located on the western edge of Santiago, some ten kilometers from downtown. The National Survey of Socioeconomic Profiles (MIDEPLAN, 2001), revealed that 18.7 percent of the borough's population lived below the poverty line. The figure is significantly higher than the poverty rate for Greater Santiago of 14.2 percent. In response to local high pollution levels and other urban problems, Pudahuel has its own Urban Regulatory Plan (I. M. Pudahuel, 2002), which proved helpful as it allowed us to identify many of the risks we wished to analyze.

\section{Hazard Selection}

Comparing multiple hazards simultaneously, rather than having participants compare them one by one provides richer insights into all rankings for a set of hazards (Roth, 1990). Hazard selection was based on three criteria:

- Perception Survey of risks of most concern to the population of Santiago (Bronfman \& Cifuentes, 2003).

- Risks examined in Pudahuel's Regulatory Plan

- Others, outside the Plan, of specific interest to the researchers, such as some environmental risks.

On the basis of these considerations, we selected the following 12 risks for the study: Suspended particulate matter, crime, illicit drugs consumption, airplane crashes, car crashes, electromagnetic fields of high-voltage transmission lines, nuclear reactor accidents, transport of hazardous materials, floods, obesity, HIV, and earthquakes.

\section{Attribute Selection}

In 1979, Slovic et al. found that lay people use not only quantitative data but also qualitative dimensions when making decisions about risk. Choosing the appropriate attributes to describe the risks is laborious (Jenni, 1997; Florig et al., 2001). For this study, the attributes selected were derived from the risk perception survey previously conducted in Santiago. In order to represent the three factors found in that study (Dread, Knowledge and Personal Effect) eight attributes were measured.

\subsection{MATERIALS}

When formulating the material, we drew upon the literature and other data sources. We also interviewed experts in the respective fields.

\section{Descriptive Material}

A descriptive paragraph was constructed for each risk. The paragraph briefly summarizes all pertinent information about the risk. In some cases, the texts help to limit the scope of the risk. For instance, for illicit drug consumption, people may associate the risk not only with drug consumption but also with drug trafficking or trafficking-related crime. Another example is car crashes: Over the past 10 years, the population of Chile increased by $9 \%$ while the number of vehicles in circulation rose by $47 \%$. Pedestrians caused close to $60 \%$ of all car crashes involving fatalities. Highway 68 and the Americo Vespucio ring road form the most significant road infrastructure in the borough.

\section{Attribute Table}


The attribute table contained simplified data. The eight attributes considered were: Greatest expected number of deaths in a single episode, personal capability of controlling exposure to a risk episode, mortality rates in Chile and in Pudahuel (deaths per 100,000 people), expert knowledge of the consequences of the risk, time lag from exposure to awareness of effects, expected number of deaths and injuries/illnesses (serious and minor). The final three attributes, expected number of deaths, serious or minor injuries and illnesses, were presented as the expected number of cases in 10 years, as people find small probabilities difficult to interpret (Siegrist, 1997). Figure 1 shows an example of the Attribute Table for car crashes.

\section{Computation of risks attributes}

Estimating mortality and morbidity for each risk often requires modeling and judgment. Data sources, assumptions, and calculations were documented separately and are available upon request. Attributes were computed based on national and local statistical data, as well as on specific studies applicable to each risk.

\section{Information on what is known about the risk and what has been done about it in the borough.}

One section provided general information, usually national then local, detailing the occurrence of the risk as well as toxicological, epidemiological, or other types of information used to estimate expected mortality and morbidity. The other section provided background of riskmanagement actions the municipality of Pudahuel or the Central Government had taken to mitigate the consequences of the risk

\subsection{SURVEY FORMATS}

To test the hypotheses of the study, we delivered the information on all 12 risks using four formats that used combinations of the different pieces of information described above.

\section{Format 1: Paragraph}

This format contains just the descriptive paragraph for the hazard. Because the descriptive material did not provide data from the attribute table, personal experiences were expected to drive comparisons and rankings.

\section{Format 2: Paragraph plus the Attribute Table}

This format includes the paragraph provided in Format 1, plus the attribute table. Because more information is provided about the risk, the group using this format would be expected to show greater consensus.

\section{Format 3: Full Brochure}

In addition to the information provided above, this format includes a longer description of what is known about the risk and any actions taken in the borough. The additional information was expected to raise concern when inadequate risk management actions had been undertaken (as judged by each participant) and to lower it when participants considered satisfactory measures were taken.

\section{Format 4: Unlabeled Table}

This format presents only the attribute table for the risk, but without identifying it. Risks were generically tagged from " $\mathrm{A}$ " to " $\mathrm{H}$ ". Participants were not able to identify the specific hazard involved, so presumably the rankings were to be performed based only on the information 
provided in the table. Participants using this format were expected to have the highest level of agreement.

Psychologists and other experts checked the material in each format several times. Each text was written in very simple, plain language.

\section{Procedure}

Residents from Pudahuel were recruited through "Neighbor-Groups" (NG). ${ }^{1}$ The only requirement was the ability to read, although completed high school education was preferred. Participants were randomly given one of the four formats, and were asked to rank the risks consistent with their own personal concerns. Subjects had to answer their questionnaires individually, without consulting any other participants.

Once participants had completed the ranking exercise, they were asked to evaluate different aspects of the procedure and their rankings. First, participants gauged how difficult the exercise had been. Second, they reported how useful different components of the materials were. Third, participants indicated how strongly they would approve or disapprove of their rankings being used as inputs to risk management decisions, and how strongly they would approve or disapprove of government agencies using this method to obtain inputs for public policy decisions.

General instructions and an explanation of the risk attributes (for Formats 2, 3 and 4) were given orally to each group prior to every session. Any doubts or queries could be raised with instructors, who were available throughout exercise. No material was provided in advance and no work was taken home. Each participant received the equivalent of US\$ 5 upon completing the exercise.

\subsection{STATISTICAL ANALYSIS}

How information delivery formats affect risk ranking was assessed using two conditions: the level of agreement of the rankings of subjects within a given group that used the same format (agreement within a group), and the level of agreement between the rankings across different groups (agreement from group to group).

\subsection{AGREEMENT WITHIN A GROUP.}

The average of all possible pair-wise Spearman correlations $(\bar{\rho})$ between the rankings of all participants within a group was computed. Significance was tested by transforming the averages to Kendall's coefficient of concordance $(\widetilde{W})$, which distributes as $\chi^{2}$ with $n-1$ degrees of freedom, where $\mathrm{n}$ is the number of risks.

\subsection{AGREEMENT FROM GROUP TO GROUP.}

To measure the degree of consensus between groups using different information formats we used two approaches.

\footnotetext{
${ }^{1} \mathrm{NG}$ are one of the basic organizations where people from the same neighborhood get together. Pudahuel has in total $35 \mathrm{NGs}$.
} 
The first approach was to compare the average Spearman correlation differences from group to group. The distribution of the sample differences was estimated using a standard bootstrapping method.

One of the advantages of this method is that inference can be conducted without knowledge of the exact properties (in small or large samples) of the statistic of interest.

We generated the estimated distribution for the difference of the Average Spearman correlations $\hat{\theta}$ for each one of the groups ${ }^{2}$. For example, to test whether there is a difference between Format 1 and Format 2, the distribution of the differences of the average spearman correlations within Format $1 \hat{\theta}_{1}^{*}$ was constructed, and then the difference of the observed values of $\hat{\theta}_{12}=\bar{\rho}_{1}-\bar{\rho}_{2}$ was tested against the critical value of the estimated distribution.

The distribution of the differences of each format was constructed under the null hypothesis that within each format the difference is zero. To obtain this distribution a new sample of 41 rankings ${ }^{3}$ from Format 1 was randomly sampled with replacement from the original samples. For this resample of 41 rankings the average pair-wise Spearman correlation was computed, let's call it $\bar{\rho}_{1}^{i}$. A second sampling was performed, also on Format 1 , in the same manner and a new average pair-wise Spearman correlation was calculated, $\bar{\rho}_{1}^{i i}$. The difference between these two average pair-wise correlations was then computed as $\hat{\theta}_{1}^{*}=\bar{\rho}_{1}^{i}-\bar{\rho}_{1}^{i i} \quad$ The entire process was repeated 1,000 times thereby generating the estimated sampling distribution of $\hat{\theta}$.

Once the estimated sampling distribution of $\hat{\theta}$ was generated, the critical value for a significance level of $\alpha$ is the $1,000(1-\alpha)$ th value of the (sorted) sampling distribution. The null hypothesis (that the difference between the average pair-wise Spearman correlations is zero) is rejected if the observed value exceeds the critical value computed above.

\subsection{SELF-REPORTED SATISFACTION WITH PROCESS AND RANKING}

This method of obtaining the risk ranking from participants can be said to be reliable if individuals are satisfied with the process and believe the results faithfully represent their concerns of the hazards. We assessed participant satisfaction explicitly, with several questions covering different aspects of their satisfaction with the ranking process asked at the end of the process.

\section{Results}

\subsection{PARTICIPANTS}

Participants were recruited from June to August 2004. In all, 195 subjects were recruited in four sessions. All participants had completed elementary school, and only 35 had not finished

2 The main tenet of the bootstrap method is that the frequency distribution of those $\hat{\theta}^{*}$ computed from the resampling is an estimation of the sample distribution of $\hat{\theta}$

\footnotetext{
${ }^{3} 41$ being the number of responses for format 1
} 
high school. Participants were aged 16 to 66 (mean $=36$ ); 67\% were female. The average monthly household income for the sample was US\$ 300 .

Depending on the format used, a single exercise took 1 to 2 hours to complete. We discarded 15 questionnaires that were either filled erroneously or incomplete. We obtained 41 rankings for Format 1, 42 for Format 2, 47 for Format 3 and 50 for Format 4.

\subsection{RANKINGS}

Table 1 and Figure 2 show the rankings of average ranking of each hazard across subjects of each group, plus the ranking based on the expected number deaths.

\subsection{AGREEMENT CONDITIONS}

The average pair-wise Spearman correlations for each of the four formats are shown in Table 2. Format 1 had the lowest level of agreement within a group $\left(\bar{\rho}_{1}=0.56\right)$, while Format 4 had the highest level $\left(\bar{\rho}_{4}=0.70\right)$. Kendall's coefficient of concordance $(\widetilde{W})$ shows that the average pair-wise correlation for the four formats is statistically different from zero.

Observed differences in agreement are shown in Table 3, along with the critical values of the estimated distribution for each format, $\hat{\theta}^{*}$. Differences in agreement from Format 2 to 1 and from 3 to 1 and 3 to 2 were not statistically significant. Format 4 differed significantly from all the other formats.

Spearman correlations of the ranking based on the average rankings (from group to group for the four formats) plus a ranking based on expected deaths are displayed in Table 4. Format 4 (Unlabeled Table) had the highest correlation with the ranking based on expected deaths $(\rho$ $=0.982)$. Rankings for Formats 2 and 3 were closer to the ranking of Format $1(\rho=0.930 ; \rho=$ $0.895)$ than to Format $4(\rho=0.720 ; \rho=0.797)$.

\subsection{SELF-REPORTED SATISFACTION WITH PROCESSES AND RANKINGS}

Table 5 shows the average responses of participants to the questions about their satisfaction with the ranking process and whether they agreed such methods should be used by decision makers in future.

For the question concerning the difficulty of the task, participants on average found the exercise relatively easy, because no average exceeded 4 (the midpoint of the scale). Statistically significant differences were encountered among participants using Format 4 when compared against Format $1(p=0.021)$, Format $2(p=0.123)$ and Format $3(p=0.007)$. Differences for participants using Formats 1, 2 and 3 were not statistically significant.

The second question, concerning satisfaction with the process, shows that participants were generally satisfied. The highest degree of satisfaction (average 6.1 out of a possible 7) involved Format 4. Statistical differences were only identified between Formats 3 and 4 ( $p=$ $0.039)$.

Finally, participants generally supported the suggestion of using the process to provide both local and central government agencies input for policy studies regarding risks. Again, Format 4 had the highest level of approval. Here, no significant differences were encountered among any of the formats. 


\section{Discussion and conclusions}

\section{Self-reported satisfaction with processes and rankings}

Format 4 was ranked as both the most difficult yet also the most satisfying format to use. There are two immediate explanations: a) people are more satisfied after finishing a task they deem more difficult, or b) the inherent difficulty in contemplating multiple attributes is quite high, so people would tend to focus on just one attribute (expected deaths) that makes the task easier and, at the same time, apparently more objective.

The results about the usability of this ranking process in public policy are extremely high. We believe this might be due to a strategic bias, reflecting not necessarily the level of satisfaction with the exercise, but rather the desire of people to be considered in public policy decisions in any way possible.

\section{Agreement within a group, and from group to group}

Consensus was found within groups independently of the amount of information about the hazards provided. All groups showed a significant agreement (statistically different from zero).

When the average rankings for formats 1,2 and 3 are examined together, we found that the top 5 positions are identical. So, it seems that for these 5 risks people most worry about, the amount of information delivered has no effect whatsoever. For the other risks, differences among all 3 formats are minor; one position and in one instance two positions.

It is interesting to compare the results of Format 4 with the other formats. First, the high level of agreement among participants who received Format 4 reinforces the hypothesis that people uses quantitative information, at least in the form it was presented in this exercise. Since rankings from Format 4 were closer to the ranking based on the expected number of deaths than any of the other seven attributes (Table 4), it would suggests that expected deaths is the most important attribute when risks are unlabeled.

The degree of consensus (measured as the average pair-wise Spearman correlation) increased from 0.56 to 0.61 when the attribute table was added to the narrative description. Further information on what measures have been taken in the borough to mitigate the effects of the hazards produced a very small change, 0.61 to 0.62 . Although the degree of consensus among participants of each group did increase as more information was provided, the differences were small and not statistically significant, except between Format 4 and each one of the others. This clearly shows that other characteristics of the risks not conveyed in the data table are important for risk ranking. Since participants were confronted with hazards they face daily, it is plausible that much of the information provided in the materials was already known to them.

Finally, the results show that the amount of information, and the way it is delivered, may affect how lay people rank risks, but not to a great extent. The question then arises: which format is the most appropriate for delivering information in a risk ranking exercise? We believe that it depends on the objective of the decision maker. If a ranking is only required to reflect citizens' concerns, a descriptive paragraph plus a table with attributes appears to be enough. Any additional information about steps taken locally to mitigate a given risk will have no significant impact on the rankings. 


\section{ACKNOWLEDGMENTS}

The authors would like to acknowledge the financial support of the Chilean Commission on Science and Technology, who funded this work through Fondecyt Project number 1020501.

We thank the referees for their comments, and the participants of a session at SRA 2004 and SRE-E 2005, where previous versions of this work were presented. We specially thank Dr. Rómulo Chumacero for his advice on statistical methods. Finally we thank the residents of Pudahuel, who kindly participated in the exercise. Any remaining errors are our sole responsibility. 


\section{REFERENCES}

Bastide, S., J.-P. Moatti, J.-P. Pages and F. Fagnani (1989) Risk Perception and the Social Acceptability of Technologies: The French Case, Risk Analysis 9: 215-223.

Bronfman, C. N., V. V. Gutierrez and L. A. Cifuentes (2003). Effect of age, gender, education and income on the perception of social and personal risk. Paper presented at the Society For Risk Analysis Annual Meeting, Baltimore, Maryland.

Bronfman, N. C. and L. A. Cifuentes (2003) Risk Perception in a Developing Country: The Case of Chile, Risk Analysis 23(6): 1271-1285.

DeKay, M. L., H. K. Florig, P. S. Fischbeck, M. G. Morgan, K. M. Morgan, B. Fischhoff and K. E. Jenni (2001) Improving Regulation: Cases in Environment, Health, and Safety, in Paul S. Fiscbeck and R. Scott. Farrow. Improving Regulation: Cases in Environment, Health, and Safety, pp.208-230. Washington, DC: Published by Resources for the Future.

Dosman, D. M., W. L. Adamowicz and S. E. Hrudey (2001) Socioeconomic Determinants of Health -and Food Safety- Related Risk Perceptions, Risk Analysis 21(2): 307-317.

Fischhoff, B. (1991) Value Elicitation: Is there anything in there?, American Psychologist 46(8): 835-847.

Fischhoff, B. (1995) Risk Perception and Communication Unplugged: Twenty Years of Process, Risk Analysis 15(2): 137-145.

Fischhoff, B., A. Bostrom and M. J. Quadrel. (1997). "Risk Perception and Communication". Oxford Textbook of Public Health. (Eds, Roger Detels, Walter W. Holland,James McEwen and Gilbert S. Omenn). Vol. 2. New York, pp. 987-1002.

Fischhoff, B., P. Slovic, S. Lichtenstein, S. Read and B. Combs (1978) How Safe is Safe Enough? A Psychometric Study of Attitudes Towards Technological Risks and Benefits, Policy Sciences 9: 127-152.

Florig, H. K., M. G. Morgan, K. M. Morgan, K. E. Jenni, B. Fischhoff, P. S. Fischbeck and M. DeKay (2001) A Deliberative Method for Ranking Risks (I): Overview and Test-Bed Development, Risk Analysis 21(5): 913-921.

Flynn, J., P. Slovic and C. K. Mertz (1993) Decidedly Different: Expert and Public Views of Risks From a Radioctive Waste Repository, Risk Analysis 13(6): 643-648.

Flynn, J., P. Slovic and C. K. Mertz (1994) Gender, Race, and Perception of Environmental Health Risks, Risk Analysis 14(6): 1101-1108.

Glendon, A. I., L. Dorn, D. R. Davies, G. Matthews and R. G. Taylor (1996) Age and Gender Differences in Perceived Accident Likelihood and Driver Competences, Risk Analysis 16(6): 755-762.

Golding, D. and e. a. S. Krimsky (1992) Evaluating Risk Communication: Narrative vs. Technical Presentations of Information about Radon, Risk Analysis 7(4): 519-529.

Gustafson, P. E. (1998) Gender Differences in Risk Perception: Theoritical and Methodological Perspectives, Risk Analysis 18(6): 805-811.

Hampson S.E., Andrews J.A., Barckley M., Lee M.E. and L. E. (2003) Assessing Perceptions of Synergistic Health Risk: A Comparison of Two Scales, Risk Analysis 23(5): 10211029.

Hitchcock, J. L. (2000) Gender Differences in Risk Perception: Broadening the Contexts, Risk: Health, Safety \& Environment 12(3-4): 179-204.

Jenni, K. E., Fischhoff, B. (1997). Attributes for risk evaluation. Unpublished doctoral dissertation. Pittsburgh: Carnegie Mellon University. 
Johnson, B. B. (2002) Gender and Race in Beliefs about Outdoor Air Pollution, Risk Analysis 22(4): $725-738$.

Kaplan, R. M. and e. a. B. Hammel (1985) Patient information Processing and the Decision to Accept Treatment, Journal of Social Behavior and Personality 1(1): 113-120.

Kraus, N., T. Malmfors and P. Slovic (1992) Intuitive Toxicology: Expert and Lay Judgments of Chemical Risks, Risk Analysis 12(2): 215-232.

Krewski, D., P. Slovic, S. Bartlett, J. Flynn and C. K. Mertz (1995) Health Risk Perception in Canada II: Worldviews, Attitudes and Opinions, Human and Ecological Risk Assessment 1(3): 231-248.

Loomis, J. B. and a. P. H. duVair (1993) Evaluating the Effect of Alternative Risk Communication Devices on Willingness to Pay: Results from a Dichotomous Choice Contingent Valuation Experiment, Land Economics 69(3): 287-298.

Lundgren, R. and A. McMakin. (1998). "Risk Communication: A Handbook for Communicating Environmental, Safety, and Health Risks". Second Edition. Battelle Press.

MIDEPLAN (2001) Caracterización Socioeconómica Nacional (CASEN) 2001, Santiago, Chile:

Morgan, M. G., B. Fischhoff, A. Bostrom, L. Lave and C. J. Atman (1992) Communicating Risk to the Public: First Learn What People Know and Believe, Environmental Science and Technology 26(11): 2048-2056.

Ilustre Municipalidad de Pudahuel, (2002) Plan Regulador Comuna de Pudahuel, Santiago.

Roth, E. (1990) What Do We Know About Making Risk Comparisons?, Risk Analysis 10(3): 375-387.

Savage, I. (1993) Demographic Influences on Risk Perceptions, Risk Analysis 13(4): 413-420.

Siegrist, M. (1997) Communicating Low Risk Magnitudes: Incidence Rates Expressed as Frequency Versus Rates Expressed as Probability, Risk Analysis 17(4): 507-510.

Slovic, P. (2000). "The Perception of Risk". London: Earthscan Publications Ltd.

Slovic, P., B. Fischhoff and S. Lichteinstein (1985) Perilous Progress: Managing the Hazards of Technology, in R W Kates, C Hohenemser and J X Kasperson (eds). Perilous Progress: Managing the Hazards of Technology. Colorado: Westview Press.

Slovic, P., B. Fischhoff and S. Lichtenstein (1980) Societal Risk Assessment: How Safe is Safe Enough?, in Jr. Richard C. Schwing and Walter A. Albers. Societal Risk Assessment: How Safe is Safe Enough?, pp.181-216. New York: Plenum Press.

Slovic, P., J. Flynn, C. K. Mertz and L. Mullican (1993) Health-Risk Perception in Canada, Ottawa: No. 93-EHD-170.

Vaughan, E. (1995) The significance of Socioconomic and Ethnic Diversity for the Risk Communication Process, Risk Analysis 15(2): 169-180.

Vaughan, E. and B. Nordenstam (1991) The Perception of Environmental Risks Among Ethnically Diverse Groups, Journal of Cross-Cultural Psychology 22(1): 29-60.

Willis, H. H. (2002). Ecological risk ranking: Towards a method for improving the quality of public participation in environmental policy. Unpublished doctoral dissertation. Pittsburgh, PA.: Carnegie Mellon University. 
Table 1: Ranking of the hazards based on the average Risk Rankings, by Format

\begin{tabular}{lccccc}
\cline { 2 - 6 } Hazard & $\begin{array}{c}\mathbf{1} \\
\text { Paragraph }\end{array}$ & $\begin{array}{c}\mathbf{2} \\
\text { Paragraph } \\
\text { Table }\end{array}$ & $\begin{array}{c}\mathbf{3} \\
\text { Brochure }\end{array}$ & $\begin{array}{c}\mathbf{4} \\
\text { Unlabeled } \\
\text { Table }\end{array}$ & $\begin{array}{c}\text { Expected } \\
\text { Deaths }\left(^{*}\right)\end{array}$ \\
\hline Suspended particulate Matter & 4 & 4 & 4 & 1 & 1 \\
Obesity & 6 & 7 & 6 & 2 & 2 \\
Car crashes & 3 & 3 & 3 & 3 & 3 \\
HIV & 5 & 5 & 5 & 5 & 4 \\
Crime & 1 & 1 & 1 & 4 & 5 \\
Illicit drug consumption & 2 & 2 & 2 & 6 & 5 \\
Flood & 7 & 6 & 7 & 7 & 7 \\
Earthquakes & 8 & 9 & 8 & 8 & 7 \\
Electromagnetic fields of high voltage & 10 & 10 & 9 & 9 & 9 \\
power lines & 12 & 11 & 12 & 10 & 9 \\
Accident from nuclear reactor & 11 & 12 & 11 & 11 & 11 \\
Airplanes crashes & 9 & 8 & 10 & 12 & 11 \\
Transport of Hazardous materials & & & & & \\
\hline Nos (*) & & & & & \\
\hline
\end{tabular}

Table 2 :Agreement among Participants within each format

\begin{tabular}{lccll}
\hline Format & $\mathbf{N}$ & $\begin{array}{c}\text { Average pair-wise } \\
\text { Spearman } \\
\text { correlation } \\
{[\bar{\rho}]}\end{array}$ & \multicolumn{2}{c}{$\begin{array}{c}\text { Kendall's } \\
\text { Coefficient of } \\
\text { Concordance }\end{array}$} \\
\hline 1.Paragraph & 41 & 0.56 & $\widetilde{W}$ & $\boldsymbol{p}$ \\
2.Paragraph+Table & 42 & 0.61 & 0.562 & 0.000 \\
3.Brochure & 47 & 0.62 & 0.539 & 0.000 \\
4.Table Only & 50 & 0.70 & 0.617 & 0.000 \\
\hline
\end{tabular}

Note: $p<0.0001$ for all Kendall's Coefficients of Concordance 
Table 3: Differences in $\bar{\rho}$ between formats

\begin{tabular}{|c|c|c|c|}
\hline & 1. Paragraph & $\begin{array}{l}\text { 2.Paragraph } \\
\text { +Table }\end{array}$ & 3. Brochure \\
\hline Critical Value $(\alpha=0.05)$ of $\hat{\theta}^{*}$ & 0.092 & 0.072 & 0.074 \\
\hline 2. Paragraph+Table & 0.06 & & \\
\hline 3. Brochure & 0.07 & 0.01 & \\
\hline 4. Unlabeled Table & $0.15^{*}$ & $0.09 *$ & $0.08 *$ \\
\hline
\end{tabular}

Table 4 : Correlations of average Rankings by Formats and by Expected Deaths

\begin{tabular}{lcccc}
\hline & 1. Paragraph & $\begin{array}{l}\text { 2.Paragraph } \\
\text { +Table }\end{array}$ & 3. Brochure & $\begin{array}{l}\text { 4.Unlabeled } \\
\text { Table }\end{array}$ \\
\hline 2. Paragraph+Table & $\mathbf{0 . 9 3 0 ^ { * * }}$ & & & \\
3. Brochure & $\mathbf{0 . 8 9 5 ^ { * * }}$ & $\mathbf{0 . 9 6 5 ^ { * * }}$ & & \\
4. Unlabeled Table & $\mathbf{0 . 7 1 3}^{* *}$ & $\mathbf{0 . 7 2 0}^{* *}$ & $\mathbf{0 . 7 9 7 ^ { * * }}$ & \\
\hline Expected Deaths & $\mathbf{0 . 7 0 8 *}$ & $\mathbf{0 . 6 9 4 ^ { * * }}$ & $\mathbf{0 . 7 6 1 ^ { * * }}$ & $\mathbf{0 . 9 8 2}^{* *}$ \\
\hline ** Correlation significant to $0.01(2$-tailed) & & & & \\
* Correlation significant to 0.05 (2-tailed) & & & &
\end{tabular}

Table 5: Summary of Self Satisfaction questions

\begin{tabular}{lccccc}
\hline & 1. Narrative & $\begin{array}{l}\text { 2. Narrative } \\
\text { + Table }\end{array}$ & $\begin{array}{l}\text { 3. Summary } \\
\text { Question }\end{array}$ & 4. Table & N \\
\hline "How difficult was it for you to & 2.81 & 3.02 & 2.76 & 3.71 & $41-51$ \\
perform the risk rankings?" (1) & $(1.87)$ & $(2.32)$ & $(1.97)$ & $(1.79)$ & \\
"How satisfied are you with your & 5.97 & 5.65 & 5.30 & 6.06 & $38-49$ \\
risk ranking?" (2) & $(1.33)$ & $(1.46)$ & $(2.15)$ & $(1.14)$ & \\
“ Would you approve the use of & & & & & \\
this process to inform decisions & & & & & \\
about risk management at:" (3) & & & & & \\
- Municipal government & 6.57 & 5.97 & 6.22 & 6.32 & $38-50$ \\
& $(0.95)$ & $(1.62)$ & $(1.43)$ & $(1.57)$ & \\
- Central Government & 6.63 & 6.47 & 6.02 & 6.83 & $38-50$ \\
& $(0.97)$ & $(1.18)$ & $(1.79)$ & $(1.37)$ & \\
\hline Notes: Averages for all participants of each format. Standard deviation shown in parenthesis. & &
\end{tabular}
(1) The midpoint of the response scale is 4 , and the end points $1=$ "an easy task" and $7=$ "a very difficult task".
(2) The midpoint of the response scale is 4 , and the end points $1=$ "very unsatisfied" and 7 = "very satisfied"
(3) The midpoint of the response scale is 4 , and the end points $1=$ "I strongly disapprove" and 7 = "I strongly approve". 


\begin{tabular}{|c|c|c|}
\hline \multicolumn{3}{|l|}{ Car Crashes* } \\
\hline Effects & \multicolumn{2}{|l|}{ Estimate } \\
\hline Deaths (over 10 years) & \multicolumn{2}{|c|}{240} \\
\hline Cases of chronic illness (over 10 years) & \multicolumn{2}{|c|}{1.400} \\
\hline Cases of slight illness (over 10 years) & \multicolumn{2}{|c|}{3.200} \\
\hline Number of Deaths resulting from one car crash & \multicolumn{2}{|c|}{60 person } \\
\hline \multirow[t]{2}{*}{ Deaths per 100,000 inhabitants per year from car crashes } & $\begin{array}{l}\text { Whole } \\
\text { Country }\end{array}$ & Pudahuel \\
\hline & 11 & 12 \\
\hline \multicolumn{3}{|l|}{ Others factors } \\
\hline The individual's controllability of exposure to a car crash is: & \multicolumn{2}{|c|}{ Medium } \\
\hline The effects associated with a car crash appear: & \multicolumn{2}{|c|}{ Immediately } \\
\hline $\begin{array}{l}\text { The expert Knowledge about the consequences of a car crash } \\
\text { is: }\end{array}$ & \multicolumn{2}{|c|}{ High } \\
\hline
\end{tabular}

Figure 1: Example of Data Table used in Formats 2, 3 and 4 


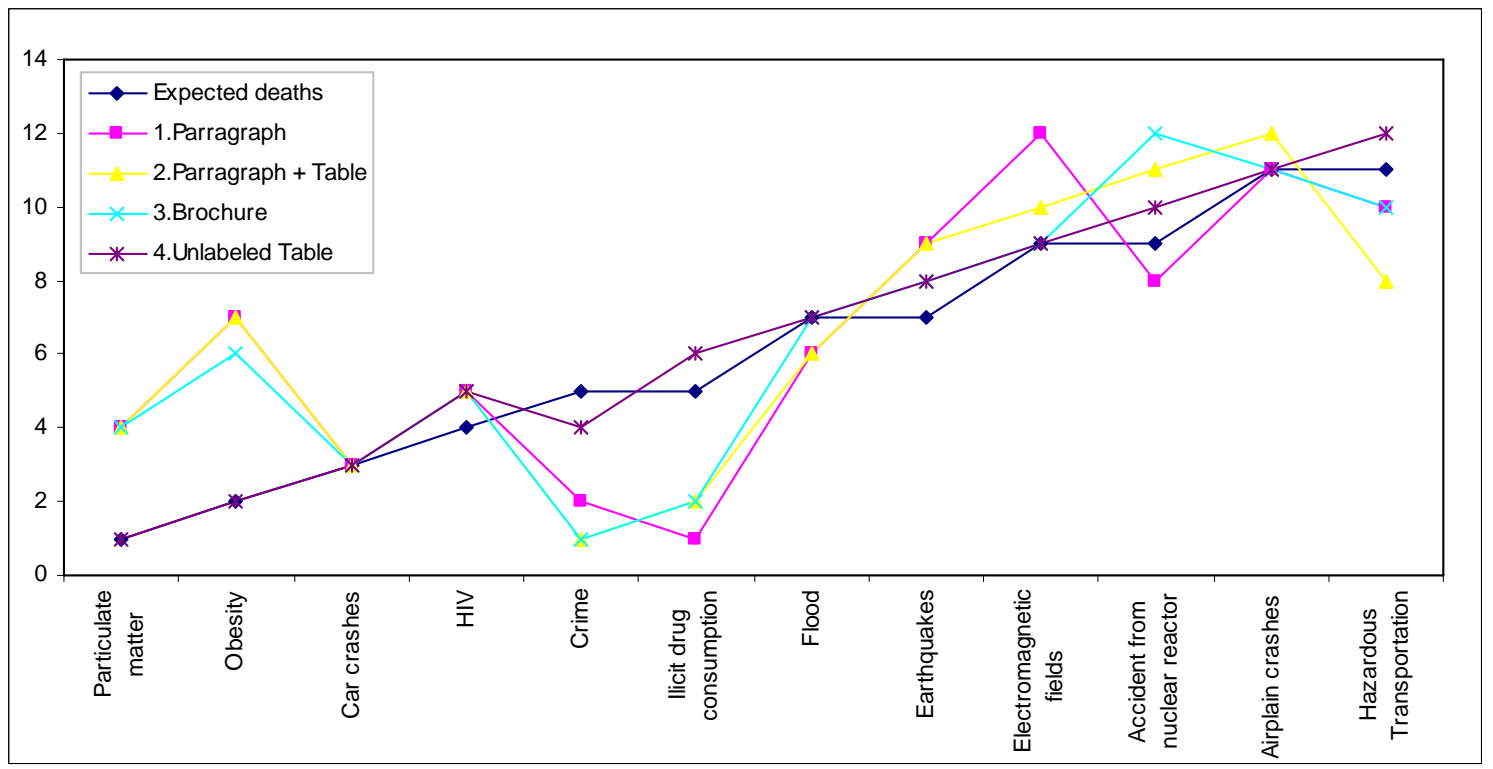

Figure 2: Ranking of hazards based on the average Risk Rankings, by Format 